\title{
Investigações sobre o Drama com crianças da Educação Infantil
}

Eixo Temático: Mediação Teatral e Metodologias de Ensino.

\section{Resumo}

Este texto trata de uma investigação, em âmbito de doutorado em teatro, realizada no ano de 2015, sobre o Drama - abordagem inglesa de ensino e experimentação teatrais - como possibilidade metodológica para um trabalho de iniciação ao teatro com crianças da Educação Infantil. Apresenta-se os principais autores, brasileiros e ingleses, que discutem esse método Bowell e Heap (2013), Farmer (2011), Neelands e Goode (2010), Cabral (2006) e Desgranges (2006), os quais embasaram a realização de 09 processos de Drama com crianças entre 02 e 06 anos de idade, em unidades públicas de ensino de Florianópolis (SC). Tornou-se evidente, ao longo da pesquisa, a proximidade do Drama com o trabalho pedagógico desenvolvido com crianças dessa faixa etária, o que levou a defendê-lo como uma abordagem que comporta os tempos e espaços próprios das infâncias, ao instigar os participantes a uma experimentação teatral distanciada da concepção de um produto artístico. Cabe ressaltar que as práticas foram conduzidas pelos professores das crianças, todos participantes do grupo teatral "Trupe da Alegria”, atuante há 07 na criação de espetáculos voltados a esse público. Por fim, um diálogo com a teoria de Lev Vygotsky ampliou as possibilidades de reflexão sobre as relações entre teatro e criação infantil.

Palavras-chave: Drama. Pedagogia do Teatro. Educação Infantil. Teatro e Infâncias.

\begin{abstract}
This text deals with an investigation, in the scope of doctorate in theater, held in the year 2015, on Drama - an English approach to theatrical teaching and experimentation - as a methodological possibility for a work of initiation to theater with children of Early Childhood Education. The main authors, Brazilian and English, discuss this method - Bowell and Heap (2013), Farmer (2011), Neelands and Goode (2010), Cabral (2006) and Desgranges (2006), which based the realization of 09 Drama proceedings with children between 02 and 06 years of age in public teaching units in Florianópolis (SC). Throughout the research, the proximity of Drama to the pedagogical work developed with children of this age group became evident, which led to defend it as an approach that includes the times and spaces proper to childhood, by instigating the participants to a theatrical experimentation distanced from the conception of an artistic product. It is noteworthy that the practices were conducted by the children's teachers, all participants in the theatrical group "Trupe da Alegria", which has been active for 7 years in the creation of shows aimed at this audience. Finally, a dialogue with Lev Vygotsky's theory broadened the possibilities for reflection on the relationship between theater and child-rearing.
\end{abstract}

Keywords: Drama. Theater Pedagogy Early Childhood Education Theater and Childhood.

Das abordagens para o ensino do teatro que me deparei na graduação e como docente, percebi no Drama um diálogo mais efetivo com as propostas pedagógicas da Educação Infantil. Para Cabral, o Drama é uma subárea do fazer teatral que se desenvolve em um “[...] processo contínuo de exploração de formas e conteúdos relacionados com um determinado foco de investigação” (2006, p. 12). Essa abordagem “[...] articula uma série de episódios, os quais 
são construídos e definidos com base em convenções teatrais criadas para possibilitar seu sequenciamento e aprofundamento.” (2006, p. 12).

Por promover uma experiência teatral a partir dos interesses da criança, dialogando com outras áreas do conhecimento, desenvolvendo-se em episódios construídos na interação dos participantes e desses com o condutor do processo, percebi que havia um potencial na proposição do Drama como encaminhamento metodológico para a iniciação teatral na Educação Infantil, tornando-se objetivo da tese.

Os objetos de análise e discussão da investigação foram 09 processos de Drama com crianças entre 02 e 06 anos em espaços de Educação Infantil da rede municipal pública de Florianópolis, em parceria com 12 educadores da Trupe da Alegria - grupo teatral formado por profissionais desse segmento nesse município que, desde 2010, é coordenado pelo autor da tese. Os experimentos foram divididos em três grupos etários: 03 processos com crianças de 02 a 03 anos, 03 com crianças de 04 a 05 anos e 03 com crianças de 05 a 06 anos.
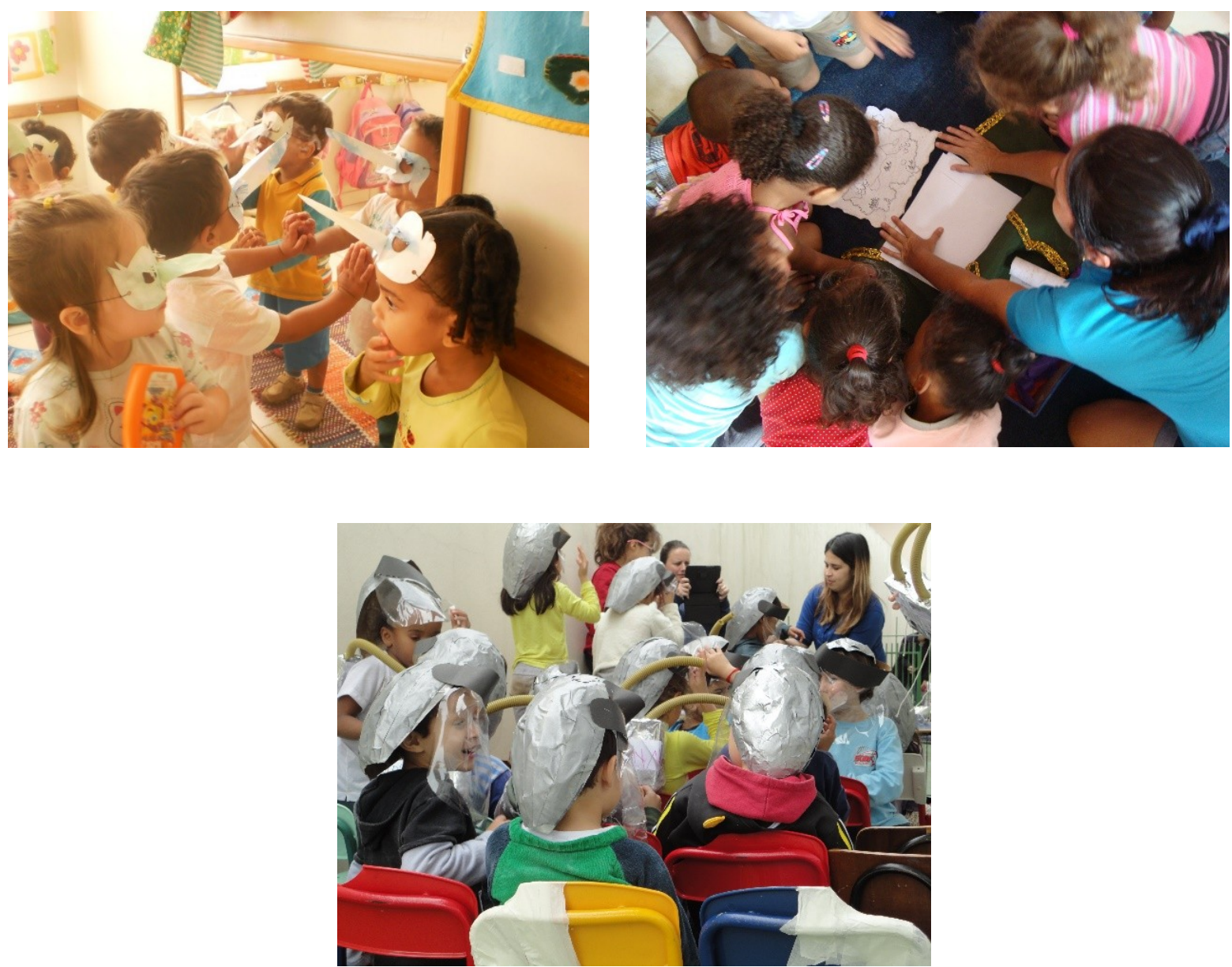
Ao participar da estruturação dos processos, planejamento das ações e acompanhamento das ações nas creches, visitava e revisitava tanto a teoria do Drama quanto as reflexões vygotskianas sobre o desenvolvimento infantil, buscando estabelecer pontes entre elas.

Utilizei-me de diversas ferramentas para coletar os materiais apresentados na tese: diagnóstico do contexto de cada grupo retratando seus objetos de interesse para, a partir deles, iniciarmos a estruturação dos processos; registros audiovisuais; observações das crianças participando das proposições feitas pelos condutores e entrevistas semiestruturadas com os profissionais que conduziram os processos.

Vygotsky tratou das especificidades da relação da criança com seu entorno nas diferentes fases, denominando-a "situação social de desenvolvimento" (1996, p. 264) e seus colaboradores refinaram a ideia ao discutirem a existência de "atividades principais", em diferentes períodos etários, que organizariam a interação da criança com o mundo.

Ao compreender quais atividades direcionam a ação da criança ao longo do seu desenvolvimento, foi possível conceber estratégias do Drama que contribuíssem com o processo de construção e assimilação de aspectos da linguagem teatral em cada faixa etária. Busquei, também, referências no trabalho de Debbie Chalmers (2010), professora inglesa de Drama que trabalha com crianças de 03 a 05 anos.

Após o desenvolvimento e análise dos processos, foi possível chegar às seguintes considerações:

*com crianças de 02 a 03 anos, segundo Vygotsky, a atividade central é a manipulação de objetos. Nesse sentido, optamos pelo uso de diferentes materialidades assim como o estímulo à imitação, uso do corpo e da voz como forma de expressão, comunicação e desenvolvimento da linguagem corporal e oral. O contato com personagens e papéis, explorando a fruição artística, também foi acentuada;

*com crianças de 04 a 05 anos, que se encontram na fase da experimentação de papéis, segundo a teoria histórico-cultural, focalizamos no incentivo à vivência de seres ficcionais como forma de estimulá-las à criação de situações fictícias. A brincadeira de faz de conta ganhou novos contornos a partir da oferta de diversas materialidades (objetos, figurinos, 
imagens, músicas, maquiagens, contação de histórias, entre outras) em conjunto com a exploração de papéis;

*com as crianças de 05 e 06 anos, a descoberta de novos saberes, por meio do estudo, passa a organizar sua relação com o mundo, assim foi possível ampliar sua experiência com a linguagem teatral através da vivência de papéis, fruição de diferentes personagens, experimentação de situações dramáticas, resolução de mistérios e desafios e apropriação de outras áreas do conhecimento como forma de ampliar o universo ficcional proposto e os saberes das crianças.

\section{Referências}

CABRAL, Beatriz. Drama como método de ensino. São Paulo: Editora Hucitec, 2006.

CHALMERS, Debbie. Drama 3-5: a practical guide to teaching drama to children in the foundation stage. Londres: Routledge, 2010.

VYGOTSKY, Lev. A formação social da mente. Rio de Janeiro: Martins Fontes, 1996. 